\title{
Education in the age of COVID-19: Understanding the consequences
}

\author{
Paul Stanistreet ${ }^{1} \cdot$ Maren Elfert $^{2} \cdot$ David Atchoarena $^{1}$ \\ Published online: 16 January 2021 \\ (c) UNESCO Institute for Lifelong Learning and Springer Nature B.V. 2021
}

There can be no doubt that the crisis caused by the COVID-19 pandemic will be looked back on as a historic moment - one that could come to be seen either as an important turning point for humanity or as a huge missed opportunity, a milestone in the story of our deterioration and mismanagement of the planet. How we respond and the actions we take now will have a profound impact on the society of the future, including the future of education. It will determine whether we continue on our current course, leading, as it would appear, to increasingly brutal, authoritarian and inequitable forms of capitalism, or whether we recognise the profound dysfunction at the heart of our socio-economic arrangements and try to create something better. To do so, we must be sure to act on the basis of values and principles that can enable us not only to build back better but to build back fairer and in a more inclusive, democratic and sustainable way. Education, of course, has a critical role in all of this, as it helps to mould these formative values while at the same time being moulded by them.

Understanding how we might change means understanding what has happened, its impact and the deeper problems it has exposed and, in some instances, exacerbated. We cannot continue to affect not to know the things that we plainly know, or deny the realities of the world we have helped create. For educators, the disruption of educational activities and practices that has resulted from the pandemic has been immense. Its impact continues to raise significant concerns. The closure of schools, universities and technical institutions around the world has disrupted the lives and learning of a whole generation of students. And while there have been many examples of institutions responding creatively to ensure continuity of learning through

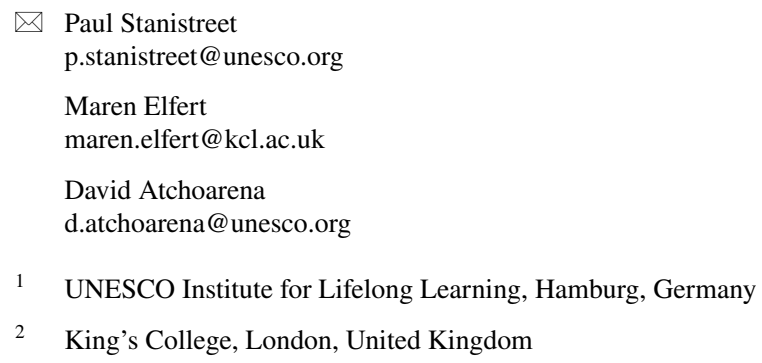


distance and online teaching, the unprecedented institutional lockdown is having a severe impact on learners.

The sudden shift to the distance mode of teaching has highlighted and compounded existing inequalities in education. A large proportion of teachers, including those teaching tertiary students at university, had little or no knowledge of the pedagogy of online teaching before lockdown, while, in contexts where significant numbers of learners are from deprived areas or homes, out of reach of technology and the internet, new gaps were created between learners. Community learning centres have also had to close their doors, disrupting access to learning for some of the most disadvantaged and marginalised adults, though many have managed the shift to online successfully, where the infrastructure allows.

Educators and psychologists are rightly concerned about the psycho-social consequences for individuals who are confined at home with limited interaction with others. For school students, the loss of contact with peers and teachers, not having a place to go every morning to learn and sometimes to receive their only meals of the day, constitute serious threats to the physical and mental health of the most vulnerable children. For teachers, the challenge has not only been pedagogical but also personal and psychological, obliging them to work in conditions where infection is more likely and emotional demands are more intense and difficult to manage.

In addition to its learning and psycho-social impacts, the COVID-19 pandemic is already generating a world economic crisis which will certainly have severe repercussions for education through possible cuts to government budgets, while the income of the many households deprived of jobs will also drop. Already neglected in pre-pandemic government spending patterns, adult education, including adult literacy, are particularly vulnerable. While typically miniscule, the share of adult education in ministry of education budgets could well be further reduced. Furthermore, the economic crisis may result in a distortion of adult education spending patterns, placing an increasing focus on vocational training, as part of active labour market policies, while literacy efforts and citizenship education continue to be overlooked. Without a significant shift in approach, the economics of lifelong learning in the post-COVID-19 era are likely to reinforce existing inequalities in terms not only of access but also retention, attainment and employment prospects. This would be a regressive outcome when the challenges we face, including the threats of democratic deterioration, demographic change, the ongoing technological revolution and, most critically, the climate crisis, make lifelong learning and the skills and capabilities it fosters more critical than ever. Finally, the pandemic could also lead to even greater inequalities between the Global North and Global South as donor countries' budgets are being severely burdened, and there is a real risk that part of the funding allocated to aid, including in education, will be redirected to domestic budgets.

When we put out the call for a special issue on "Education in the Age of COVID19" in March 2020, we knew very little about the full impact of this crisis on education and on societies at large, but we were deeply worried about all of these issues and eager to hear from colleagues around the world. The response was overwhelming - we received more than 150 abstracts from countries across all continents. It was incredibly inspiring and sometimes, in some respects, also disheartening for us to read the abstracts from educators and education scholars, many of whom 
were troubled about the impact of worldwide lockdowns on teachers and learners, although some of them reported positive developments or recognised in the crisis a moment of opportunity to reflect on and advocate for a better future.

Our decision to publish two double special issues enabled us to accommodate more articles than originally planned, and meant we were not required to reject a large number of potentially insightful articles. The selected articles were written in the spring of 2020 and revised over the summer. Twelve are published in this double special issue, focused largely on understanding the impact of the pandemic on education, and the remainder will appear in the second double special issue in April 2021, highlighting future trends and possibilities and the challenges of recovery. While the articles inevitably give us an impression from the early stages of the pandemic, the issues they raise remain highly relevant, particularly as, in many countries, a second lockdown has lately tightened recently loosened regulations and the challenges and opportunities discussed in the articles have not lost any of their actuality or applicability.

We were very pleased to see that many of the contributions were products of collaborative efforts, as we received a considerable number of co-authored articles, several of them by authors from different countries, some from mixed groups of male and female scholars, and many of them co-authored by two or more women, a particularly positive signal in a pandemic that confines us to "lone working" and has disproportionately affected women (Del Boca et al. 2020). ${ }^{1}$ Out of 24 submitted articles, only six are single-authored. Some of the co-authored articles involve collaborations between faculty members and students. In terms of disciplinary, theoretical and methodological orientation, this special issue includes empirical sociologically oriented studies (Bonal and González) and non-empirical philosophically and critical theory-oriented articles (Eschenbacher and Fleming; Bjursell; Bainbridge), as well as a number of articles written from the perspective of educators and/or academics investigating, based on research and/or experience, changing educational, academic and research practices during the pandemic (Béché; Choi, Tessler and Kao; Galloway et al., Goebel et al., Käpplinger and Lichte; Kaiper-Marquez et al.; Lyu et al.). Some recognise in the pandemic an opportunity to challenge the ways in which our institutions function, and reflect critically on how they might change and the possible ways ahead (Bainbridge; Goebel et al., Green et al.).

Despite the differences in orientation, some common themes emerge. Several articles discuss how the pandemic shines a light on and exacerbates existing inequalities and how the shift to online learning exposes inadequacies of schools and adult and higher education systems (Bonal and Gonzalez, Béché, Galloway et al., Käpplinger and Lichte). Other articles point to the importance of transformative and reflective learning and call for a more sustainable education in a time of disorientation and crisis (Bainbridge; Bjursell; Eschenbacher and Fleming; Goebel et al.,

\footnotetext{
${ }^{1}$ Del Boca, D., Oggero, N., Profeta, P., \& Rossi, M.C. (2020). Women's work, housework and childcare, before and during Covid-19. IZA Discussion Paper No. 13409. Bonn: Institute of Labor Economics (IZA). Retrieved 25 November 2020 from https://papers.ssrn.com/sol3/papers.cfm?abstract_id=36366 38\#.
} 
Käpplinger and Lichte). Another key issue raised by several authors is the importance of creative solutions for community and intergenerational learning and the need to strengthen communities (Bjursell; Choi, Tessler and Kao; Galloway et al., Kaiper-Marquez et al.).

We begin with an article from Catalonia entitled "The impact of lockdown on the learning gap: Family and school divisions in times of crisis". Xavier Bonal and Sheila González draw on a survey they conducted in March 2020. It presents a wealth of findings that readers are encouraged to explore for themselves. The main insight of their study, however, is that the pandemic has further exacerbated already alarming socio-economic disparities between students from different backgrounds - a story that will be recognised in every world region and every country.

The article by Saskia Eschenbacher and Ted Fleming, entitled "Transformative dimensions of lifelong learning: Mezirow, Rorty and COVID-19”, takes a very different approach. The authors reflect on lifelong learning and the relevance of transformative learning in times of COVID-19, placing the work of Jürgen Habermas and Richard Rorty in a dialogue with Jack Mezirow's transformative learning theory in order to do justice to the complexities of disorienting dilemmas, contradictions, ambivalences and meaning-making in a world where "not-knowing is the new normal".

Cecilia Bjursell's article, entitled "The COVID-19 pandemic as disjuncture: Lifelong learning in a context of fear", also takes a critical view of the deployment of lifelong learning and the measures undertaken to ensure continuity of learning during the pandemic. Drawing on Peter Jarvis's use of the concept of disjuncture, Bjursell warns that the learning that occurs during the pandemic, in particular the measure of "social distancing", can result in outcomes that are not to the benefit of either the individual or society. Concerned that in a context of fear, learning may result in a narrowing of mindsets and a rejection of collective efforts and solidarity between generations, Bjursell highlights a need to engage in reflective learning to learn to be a person in a post-pandemic society.

Anna Kaiper-Marquez, Emily Wolfe, Carol Clymer, Jungeun Lee, Elisabeth Grinder McLean, Esther Prins and Tabitha Stickel examine how the Goodling Institute for Research in Family Literacy at The Pennsylvania State University in the United States has responded to the pandemic by swiftly converting its face-to-face family literacy classes into emergency remote instruction, for eight immigrant families, using online platforms. In their article entitled "On the fly: Adapting quickly to emergency remote instruction in a family literacy programme", the authors draw a generally positive conclusion of the ability of the programme to offer a meaningful learning and community experience throughout the pandemic, in spite of the difficulties it continues to pose. Although they also present challenges encountered by the instructors and the families involved in the programme, one of their key messages is that the experience has led instructors and learners to find creative solutions that might benefit learning in the longer term: "the shift to online, remote instruction encouraged instructors to find new ways to promote learning ... that will continue when face-to-face classes reconvene."

The next article, by Meera Choi, Hannah Tessler and Grace Kao, is entitled "Arts and crafts as an educational strategy and coping mechanism for Republic of Korea 
and United States parents during the COVID-19 pandemic". It explores how families have found ways of providing valuable educational activities to compensate for school closures. Focusing on the United States and South Korea, the authors show that toy sales and arts and crafts activities on the internet, such as online museum and virtual zoo tours, have surged during the pandemic. In South Korea, the government has invested in supporting cultural activities and implemented drive-through or walk-through toy rental systems. The authors also emphasise the role of cultural capital and parents' and children's socio-economic background and reflect on the question whether the crisis might lead to long-term changes in parenting and sustained interest in cultural resources. The authors' findings have implications for the importance of arts and the humanities - fields that have been neglected and are increasingly marginalised in schools and educational institutions worldwide - in the educational experience of children.

In "Digging our own grave: A Marxian consideration of formal education as a destructive enterprise", Alan Bainbridge offers a Marxian analysis of the erosion of education by capitalism and neoliberalism. His article challenges readers to realise how much our view of education is influenced by capitalism, and argues that we need to move away from neoliberalism to achieve a more sustainable and sustaining education - an education for a "long life", as he calls it. The article encourages us to look through a different lens in order to achieve the kind of shift we need to achieve a greener, more sustainable way of being, considering the COVID-19 crisis but also looking beyond it to the climate breakdown and the likely spread of other zoonotic diseases.

The next article, "Cameroonian responses to COVID-19 in the education sector: Exposing an inadequate education system" by Emmanuel Béché, presents and discusses the responses of education authorities to ensuring continuity of formal education in Cameroon. Despite efforts that involved a variety of initiatives, Béché points to the educational inequalities revealed by the crisis and the problems of exclusion and disorganisation which plague the education system and the day-to-day lives of people in the country. Looking ahead and beyond the current pandemic, the author argues that integrating distance learning technologies and improving access to socio-educational services are essential in ensuring that education in Cameroon is able to respond to the crises of the future.

Bernd Käpplinger and Nina Lichte's article presents the findings from the first stage of a Delphi study asking adult educators around the world about their views on the consequences of the COVID-19 crisis for adult education. The quote in the title of their article, "'The lockdown of physical co-operation touches the heart of adult education': A Delphi study on immediate and expected effects of COVID19 " is taken from one of the research participants' responses. Adult educators express concern about an irreversible shift to distance and digital learning, further neglect of adult education in funding priorities (foreseeing a prioritisation of health), increased vocationalism, and lack of critical thinking and risk aversity. Respondents saw COVID-19 as a magnifying glass that accelerates existing tendencies such as vocationalism or the digital turn. Thus, social inequality is expected to increase as a future effect. Drawing on their research participants' responses, Käpplinger and Lichte are more sceptical in their assessment of the 
impact of the pandemic on adult learners than Kaiper-Marquez et al., who present a comparatively positive picture of the resilience of adult education programmes in times of crisis.

The next article, "Academic conferencing in the age of COVID-19 and climate crisis: The case of the Comparative and International Education Society (CIES)", authored by Janna Goebel, Caroline Manion, Zsuzsa Millei, Robyn Read and Iveta Silova, discusses the impact of the COVID-19 pandemic on academic conferencing. Janna Goebel and her co-authors were all highly involved in the organisation of the 2020 Conference of the Comparative and International Education Society (CIES), an annual gathering which is among the most important international events for comparative education scholars and academic journals such as IRE. The authors, among them current CIES president Iveta Silova, were faced with the challenging task of moving the conference online in the space of a few weeks rather than cancelling the event, which was the most common response of other conferences and events affected by lockdowns and travel restrictions. This article is an important contribution not only because the CIES experience will serve as a reference for future academic conferencing, but especially because the authors reflect more broadly on the ethical implications of large academic conferences in a time of climate crisis and the Western knowledge hegemony perpetuated by these events.

In this sense, it relates to the next article, "Education in uncertainty: Academic life as Indigenous health scholars during COVID-19" by Tracey Galloway, Andrea Bowra, Tenzin Butsang and Angela Mashford-Pringle. From the perspective of scholars, community workers and researchers in the field of Indigenous health in Canada, they reflect on the profound impact the pandemic has had on their teaching and learning, research and interactions with Indigenous communities, with a particular focus on the experiences of emerging scholars, who feel the loss of conferences as "significant academic experiences" particularly strongly.

The article by Keyi Lyu, Ying Xu, Hao Cheng and Jiacheng Li focuses on intergenerational learning in China. Based on a research study conducted with teachers and families in seven schools, "The implementation and effectiveness of intergenerational learning during the COVID-19 pandemic: Evidence from China" sheds light on intergenerational learning between grandparents and their grandchildren. The authors' suggest that both generations gained from the extended periods of time they spent together during lockdown, in terms of the transmission of knowledge about health, life skills and values, and that the interactions led to shifts in perspectives on learning and to greater intergenerational understanding, improving the relationships between grandparents and grandchildren.

Finally, the contribution by Crystal Green, Laurelyn Mynhier, Jonathan Banfill, Phillip Edwards, Jungwon Kim and Richard Desjardins represents a very suitable conclusion to this first special issue on Education in the Age of COVID-19. In "Preparing education for the crises of tomorrow: A framework for adaptability", the authors present a framework for organising education in times of risk, again encompassing but also looking beyond the current crisis. Highlighting cooperation, inclusion and flexibility as key components of educational adaptability, the authors argue that "[i]n the context of COVID-19, the lack of collective culpability for the sustainability of education is causing educational systems to collapse. For this reason, we deem collectivisation of risk a key component of our proposed Framework for adaptability." 
Taken together, the articles of this issue (as well as the upcoming second compilation scheduled for April 2021) comprise a wealth of insights, experiences, reflections, warnings and visions for the future that can help us cope with, make sense of and move beyond this crisis. The issue can be used as a toolbox of resources to support this process of recovery and renewal. It also has useful things to say about how to prepare for the global crises that are to come (as, inevitably, they will) - and in particular the growing climate crisis from which, unlike the current crisis, no recovery will be possible if we do not act decisively now. In coming to terms with COVID-19 we must also strive to build a society capable of addressing these issues, one characterised by a renewed focus on solidarity, within and between nation states, and among people.

We as editors have learned so much from these contributions, which we strongly recommend to your attention. We thank the contributors for sharing their work and insights, and for doing so in such a speedy and persuasive way. They have made this timely and important special issue, and its forthcoming sister issue, possible. The pandemic and its implications for education will be written about a great deal in the coming months and years, but this issue offers an indispensable snapshot of a world coming to terms, for the first time, with a difficult new reality.

Publisher's Note Springer Nature remains neutral with regard to jurisdictional claims in published maps and institutional affiliations.

Paul Stanistreet $\mathrm{PhD}$, is Head of Knowledge Management and Communications at the UNESCO Institute for Lifelong Learning (UIL) in Hamburg and Executive Editor of the International Review of Education - Journal of Lifelong Learning (IRE). He has worked in education policy, research and advocacy for almost 20 years, including for the National Institute of Adult Continuing Education (NIACE) in the UK. He edited NIACE's journal, Adults Learning, from 2002 to 2014, and has published a blog on adult education - https://thelearningage.wordpress.com/ - since 2012. His early work background was in newspaper journalism, after which he studied philosophy as a mature student. He gained his $\mathrm{PhD}$ from the University of Glasgow in 1999.

Maren Elfert $\mathrm{PhD}$, is Lecturer in Education \& Society in the School of Education, Communication and Society at King's College London, and a 2018 National Academy of Education/Spencer Postdoctoral Fellow. Before pursuing doctoral studies, she worked for more than a decade as a member of the professional staff at the UNESCO Institute for Lifelong Learning (UIL) in Hamburg, Germany. In 2020, she joined the editorial team of the International Review of Education - Journal of Lifelong Learning (IRE) as Submissions Editor. Her research focuses on global governance of education and the influence of international organisations on educational ideas and policies.

David Atchoarena is Director of the UNESCO Institute for Lifelong Learning (UIL) in Hamburg, Germany. He was appointed in April 2018. He was previously Director of the Division for Policies and Lifelong Learning Systems at UNESCO, including Policy, Higher Education, Technical and Vocational Education and Training (TVET) and Technology in Education. Prior to working for UNESCO, including many years at the International Institute for Educational Planning (IIEP) as programme specialist and later as Team leader, Mr Atchoarena served as Chargé de Mission at the National Agency for Lifelong Education (ADEP) of the French Ministry of Education and as project coordinator in the Ministry of Finance and Planning in Saint Lucia. He holds a doctorate in Economics from the University of Paris I (Panthéon-Sorbonne). 